\title{
Exploring The Factors Influencing UPM English Language Faculty Members' Adoption And Integration Of Web-Based Instruction (WBI)
}

Sima Sayadian, University Putra Malaysia, Malaysia

Dr.Jayakaran Mukundan, University Putra Malaysia, Malaysia

Dr.Roselan Baki, University Putra Malaysia, Malaysia

\begin{abstract}
Technology, if integrated effectively, has been found to influence students' academic performance, develop their higher order thinking and problem solving, improve their motivation, attitude, and interest in learning, and help them prepare for the workforce as well as address the needs of low performing, at-risk, and learning impaired students (Center for Applied Research in Educational Technology, 2005). This paper reports the findings of the study trying to investigate the application and integration of web based instruction by University Putra Malaysia (UPM) lecturers in Serdang, Malaysia. A questionnaire which included the items from the short form of the Moore and Benbasat (1991) instrument as well as some demographic questions was administered to UPM lecturers in Malaysia. Data collected through the survey questionnaire was used to examine the factors influencing the University Putra Malaysia (UPM) lecturers' perception about application and integration of web based instruction. Our analysis of the data suggests that the innovation adoption variables of relative advantage, compatibility, visibility, ease of use, results demonstrability, and trialability should be considered by university lecturers seeking to increase the rate of adoption of e-Learning within their organisation.
\end{abstract}

Keywords: perceived characteristics of innovating model (PCIM), Technology Application, Web based Instruction, Teaching English as a Second Language

Today, computers and telecommunications are a fact of life as basic as electricity. They have altered the daily work of large businesses and industry. Yet why is it that with all the talk of school reform and information technologies over the last decade, computers are used far less on a daily basis in classrooms than in other organizations? (Cuban (1993):p.185).

\section{INTRODUCTION}

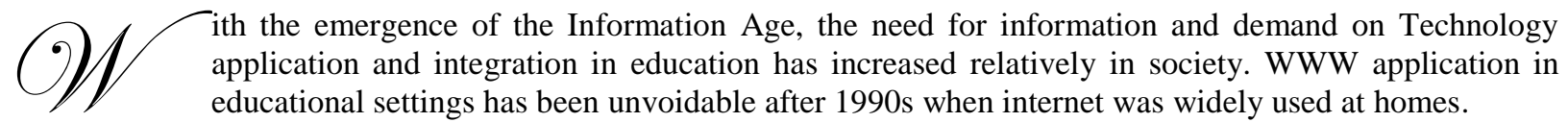
Consequently, technology can be assumed as one of the inevitable prerequisites of today's world. Because technologies are evolving at an extraordinary rate, there now exists a digital generation that is redefining computer literacy and the meaning of technology integration in schools (Brogan, 2000).

Wang, X, Wang, T. and Ye (2002) suggested that Knowing how much teachers understand about technology and instructional materials and how they use these technologies and materials in classrooms are essential for staff development programs. 
Teachers are expected to develop independent, creative, computer-knowledgeable students that can learn in dynamic environments (Gemeinhardt, 2002; McCullen, 2001). However, with all the attention on instructional technologies, the influence of these technologies on the tertiary level classrooms has not been fully assessed.

Marcinkiewicz (1993) states that teachers, not technology, hold the key to achieving successful integration. For educators and researchers to understand how to achieve integration, researchers need to study teachers and what makes them use computers.

Recent research indicates that there are a few teachers who are described as exemplary in their use of computers for instruction and learning.

How then do faculty members make decisions to adopt or reject web-based instruction? In their action research, Groves and Zemel (2000) addressed the question of the perceived barriers and needs for technology adoption and use in higher education. Their findings show that in order to use technology in teaching, respondents wanted accessible hardware, training, and discipline-specific media that are easy to use. Such requirements are available in the universities yet there are faculty members who are still reluctant to adopt instructional technology especially web-based instruction, which is rapidly becoming one of the major avenues to deliver courses to students (Nations, 2000).

A lot of research evidence has started to accumulate regarding the positive influence of technology on learning and teaching. Technology, if integrated effectively, has been found to influence students' academic performance, develop their higher order thinking and problem solving, improve their motivation, attitude, and interest in learning, and help them prepare for the workforce as well as address the needs of low performing, at-risk, and learning impaired students (Center for Applied Research in Educational Technology, 2005).

Technology has also been proved to positively influence the teaching process. Technology has the potential to shift the teaching process from a teacher-centered approach to a learner-centered approach (Knap \& Glenn, 1996). Technology can also transform the role of teachers from one of sole provider of information to one of facilitator of learning experiences. In other words, technology transforms the instructor's role from being a "sage on the stage" to being a "guide on the side" (Collison, Elbaum, Haavnd, \& Tinker, 2000). The individualization and interactivity features that technology can bring to the learning/teaching environment have been found to increase instructional effectiveness, ensure that all students learn, and reduce time needed to reach instructional objectives (Fletcher, 2003).

\section{PURPOSE OF THE STUDY}

The purpose of this study is to investigate the factors that influence the adoption and integration of WebBased Instruction (WBI) by English language university lecturers in Malaysia. The study intends to: (1) investigate the relationship between the five attributes of the Diffusion of Innovations Model (relative advantage, compatibility, complexity, trialability, and observability) and WBI adoption and integration by TESL(Malaysian) English language lecturers, (2)introduce the most and least frequent attribute of Diffusion of Innovation Model among UPM English language university lecturers, and (3) explore the relationship between English language lecturers' demographic variables (gender, age, academic rank, nationality, major, country of graduation, and years of teaching experience) and their adoption and integration of WBI in the Malaysian and Iranian universities.

\section{STATEMENT OF THE PROBLEM}

Research in the past decade has shown that computer technology is an effective means for widening educational opportunities, but most teachers neither use technology as an instructional delivery system nor integrate technology into their curriculum

Malaysia, being one of the leading and active counterpart in ASEAN, is considered to be applying technology more remarkably than many other Asian countries. However, similar to many other Asian and even 
western countries, technology in general and web based instruction in specific is not fully applied and integrated in its language classes as it should be.

This may be due to the fact that it is unclear how learning environments are changing when computers are integrated in the classroom. Educational researchers (Naidu, Cunnington, \& Jasen, 2002; Masters \& Yelland, 2002; Pahl, 2003; Patten, 1997) stress that there is little knowledge of the impact that integrating technology brings to teaching practices, and most educators are unaware of how it affects their teaching. In addition, much of the literature on technology integration examines only two areas: (a) the learner's achievement after using a particular technology (Thelwall, 2000; Heinecke, Blasi, Milman, \& Washington, 1999) and (b) the assessment of the technology program or tool being used (Passey, 1999; Scanlon, Jones, Barnard, Thompson, \& Calder, 2000), especially compared with traditional face-to-face instruction (Lee, 2001).

Although much of the literature shows positive attitudes among faculty members in Asian countries such as Saudi Arabia, USA(Wanjira Kinuthia,2005) Taiwan, Singapore, China Cheng, Y., (2003).,Turkey(ESRA YECAN, 2005) toward technology integration (Addawood, 1990; Al-Amri, 1993; Al- Erieni, 1999; Al-Fulih, 2002; AlKahtani, 2001; Alharbi, 2002; Allehaibi, 2001; Al Saif,2005; Al-Kahtani, 2006), Malawi(Clemence Michael Kadzera,2006) many English language lecturers still seem to be reluctant to adopt and integrate WBI technologies into their teaching process. This study attempts to investigate the factors that influence the adoption and integration of WBI by English language faculty members in Iranian and Malaysian universities.

The Intemet, since its formation in the 1970s, has grown sfronger and stronger (Willis, 2004). The Intemet and the World Wide Web become one of the technologies most rapidly adopted by society. The WWW provides large amount of information and tons of resources that educators and leamers can have access to and utilize in their teaching and leaming (Willis, 2004).

\section{RESEARCH QUESTIONS}

This study tends to investigate the factors that influence the adoption and integration of WBI by English language lecturers in TEFL contexts in Malaysia .Therefore, the study explores the following research questions:

1. Is there a significant relationship between the attributes of the Diffusion of Innovations Model (relative advantage, compatibility, complexity, trialability, and observability) and WBI adoption and integration by Malaysian English language lecturers?

2. Is there a significant relationship between English language lecturers' demographic variables (gender, age, academic rank, nationality, major, country of graduation, and years of teaching experience) and their WBI adoption and integration in Malaysian universities?

3. What are the most and least frequent types of WBI applied by UPM university lecturers?

\section{SIGNIFICANCE OF THE STUDY}

English Language Centres and institutions use various technology applications in language learning, such as the Internet, language learning software, and Blogs as a way to prepare students for their college experience, while continuing their language learning.

However, there has been limited research about teachers' perceptions or reactions to technology application and integration in language learning.

The findings of this study will hope to be effective in the way that It is hoped it will provide some insights to decision-makers and professionals in the Iranian and Malaysian Higher Education Ministry and universities as well as curriculum designers and all involved in the process of English language teaching as Second or Foreign language to:

1. Determine the current state of English language lecturers' perception about WBI application and integration in language classes. 
2. Investigate the variables that support or impede English language lecturers from effective integration of WBI in their teaching.

3. Provide some suggestions and recommendation on WBI application and integration.

4. Provide a background for future reference and further research studies in this area.

5. provide insights to ESL/EFL lecturers on choosing and applying web based activities and exercises into the curriculum.

Throughout educational institutions, educators and administrators are trying to evaluate the benefits of learning technologies in the classroom because of the enormous economic investments districts are making in technology (Cunningham, 2001; Healey, 1998; Henry, 1997; Kleiman, 2000).

What is missing in the literature is an evaluation of how computers are being used in the learning process and the practices necessary for teachers to effectively integrate learning technologies in the classroom.

If the research can clarify and provide a snapshot of computers being integrated in the curriculum, then educators will have the ability to analyze what changes may need to occur in order to promote meaningful technology integration. Simply having computers in place does not cultivate a different learning environment. Ultimately, the research will add to the literature the essential elements necessary to cultivate a technology-rich learning environment so classrooms and technology labs can be used more effectively to produce learners equipped for the 21 st century.

But teacher training programs often fail to teach their students how to incorporate technology into their teaching (Basinger, 2000). Teachers are expected to use technology but are themselves not fully exposed to all the ramifications of computer-based learning, including online instruction.

Faculty members did not feel that Web-based courses were as effective in strengthening group problemsolving skills, improving verbal skills, or helping students deliver better oral presentations (NEA: National Education Association, 2000).

J. Bennett and L. Bennett (2003) observed: when one is confronted with new technology, he or she goes through an adoption decision process in which he or she gathers information, tests the technology, and then considers whether it offers sufficient improvement to warrant the investment of time and energy that is required to add it to his or her repertoire of skills. (p. 55-56).

\section{INSTRUMENTS:}

The instrument applied in this study was composed of three parts: .

\section{Part 1: Adoption and Integration WBI}

The first part of the questionnaire consisted of 2 sub parts, the first part of which was designed to identify the participants' experience with WBI including how long they had been integrating WBI in their teaching and how frequently they integrated WBI technologies in their teaching. However, the second subpart included different types of web based instruction applied and integrated by the participants while teaching in their classes.

\section{Part 2: Attributes of the Diffusion of Innovations}

The second part was a modified version of Roger's model of attributes of innovation, consisting of 20 items designed to identify the factors that influence the participants' adoption and integration of WBI. The five attributes, as identified by Rogers (1995), were: (1) relative advantage, (2) compatibility, (3) complexity, (4) trialability, and (5) observability. These items were adapted from Moore and Benbasat (1991) who developed an instrument to measure the perceptions of adopting an informational technology innovation based on Rogers' (1995) five attributes of the Diffusion of Innovations Model.

\section{Part 3: Demographic Variables}

The third and final part consisted of eight items designed to gather some demographic information about participants; namely, gender, age, academic rank, nationality, major, country of graduation, and years of teaching experience. 


\section{PARTICIPANTS}

Forty two English Language university lecturers from University Putra Malaysia(UPM) were selected .The Population included 21 female and 21 male participants and they came from different academic ranks, major, teaching experience as well as the experience of technology(WBI) integration in language classes.

\section{METHODOLOGY AND PROCEDURE}

The modified questionnaire was first tested to make sure about its reliability through Crenbach's Alpha the result of which proved the test to be reliable enough (0.867) in order to proceed with the research questions and objectives of the study. The questionnaire was distributed by the researcher among UPM English language lecturers from both the faculty of Educational Studies and faculty of Modern Languages and Communication. There were 60 lecturers asked to take part in the study, however, only 42 were willing to participate. Later the questionnaires were thoroughly examined, and data were retrieved and eventually SPSS software, edition $14^{\text {th }}$, was applied in order to analyze and interpret the obtained results.

\section{RESULTS AND DATA ANALYSIS}

The participants were asked to choose and mark the most and least frequent type of web Based Instruction (WBI) they applied and integrated while teaching in their classes. Table 1 presents the data and illustrates the most frequent type to be WWW (M = 3.69, SD = 1.29). and the least frequent one as Audio conferencing and Videoconferencing $(\mathrm{M}=3.69, \mathrm{SD}=1.29)$

Table 1: Mean and SD of the WBI scales

\begin{tabular}{|l|c|c|}
\hline \multicolumn{1}{|c|}{ Variables } & M & SD \\
\hline WBI & 3.40 & 1.57 \\
\hline Course web & 2.88 & 1.31 \\
\hline WWW & 3.69 & 1.29 \\
\hline Mailing & 2.54 & 1.33 \\
\hline News group & 2.21 & 1.22 \\
\hline Gopher & 1.66 & 1.53 \\
\hline Search & 3.52 & 1.55 \\
\hline Digital & 2.9 & 1.55 \\
\hline On line paper & 3 & 1.41 \\
\hline Power point & 3.19 & 1.46 \\
\hline Pdf & 2.95 & 1.36 \\
\hline Audio-vediostreaming & 2.28 & 1.29 \\
\hline Im & 1.85 & 1.03 \\
\hline Audio & 1.61 & .98 \\
\hline Vedio & 1.61 & 1.03 \\
\hline FTP & 1.73 & 1.38 \\
\hline Course Management & 2.28 & 1.52 \\
\hline CMS & 2.23 & \\
\hline
\end{tabular}

Table2: Subscales of Attributes of Diffusion Model

\begin{tabular}{|l|c|c|}
\hline \multicolumn{1}{|c|}{ Variables } & M & SD \\
\hline Total score of Attribute of diffusion & 3.49 & .495 \\
\hline Relative Advantage & 3.89 & .779 \\
\hline Compatibility & 3.79 & .676 \\
\hline Complexity & 3.03 & .36 \\
\hline Trailibility & 3.39 & .792 \\
\hline Observability & 3.35 & .691 \\
\hline
\end{tabular}




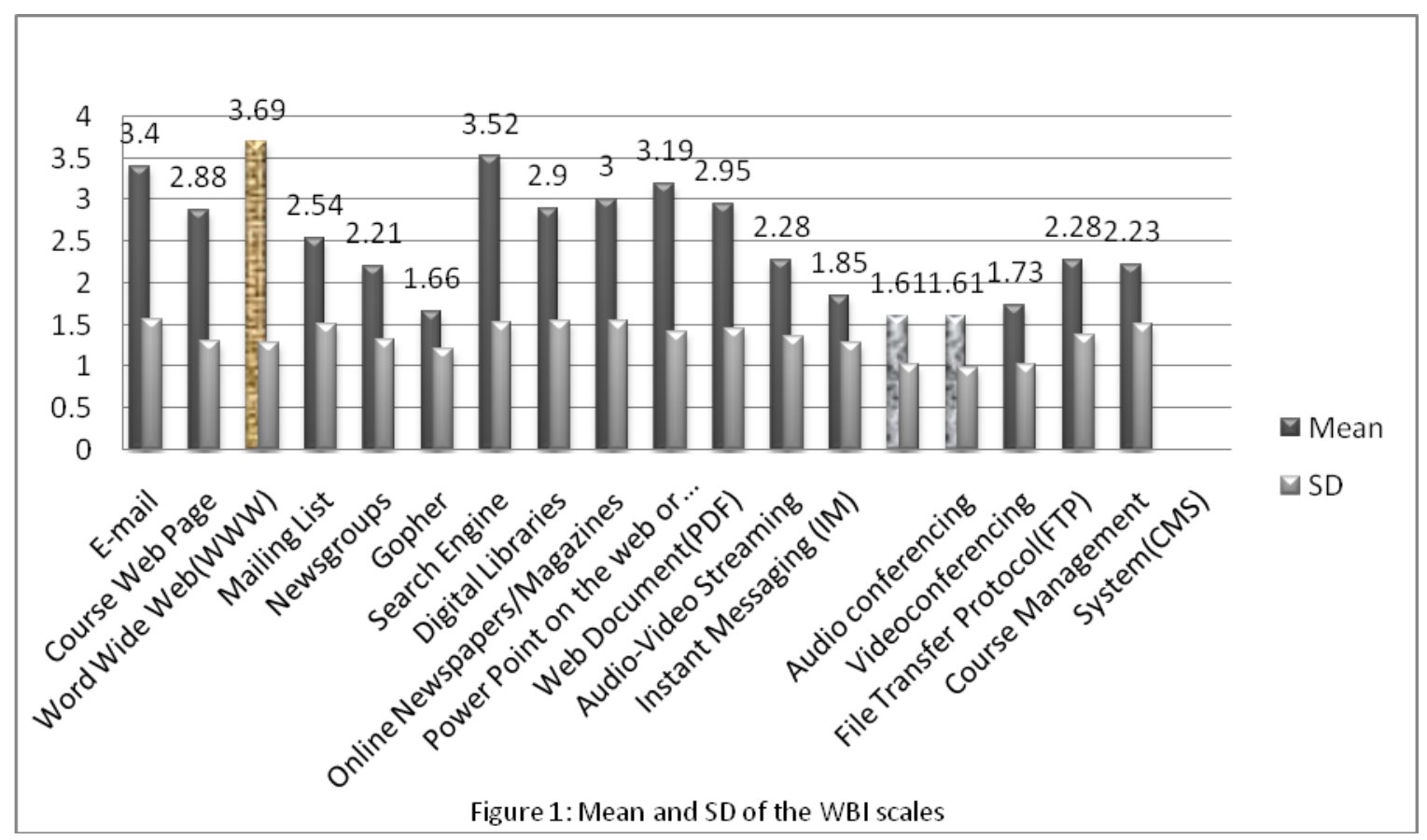

The data was also analyzed in order to find out about the most and least frequent attributes of diffusion of innovation model to be accounted for WBI integration in language classes. The results showed that UPM lecturers applied WBI in their classes simply due to its relative advantage, however, they avoided to integrate WBI in their classes because of its complexity. Table 2 displays the result.

T-test was conducted in order to find out the difference between gender and WBI application, however, no significant difference was observed $(\mathrm{t}=0.435, \mathrm{p}=0.666)$.

In order to find out the difference between the participants' academic rank and WBI application, ANOVA was carried out , and no significant difference was observed: $F(4.37)=0.751, \mathrm{p}=0.564$.

To discover the difference between the participants' major and WBI application, ANOVA was used, however, no significant difference could be observed between the mean of WBI and participants' major. $\mathrm{F}(3.37)=$ $0.328, \mathrm{p}=0.805$.

Similarly, Pearson showed that no significant relationship was found between teaching experience and WBI application. $\mathrm{r}=-.066, \mathrm{p}=0.683$.

\section{CONCLUSION}

The findings of this study supported the findings of the study by Catherine Mwaura conducted in Ohio in 2004 in which she found Relative Advantage to be the main reason to encourage faculty members to integrate web based instructions in their classes and similarly, he found out complexity to be the main attribute of technology to prevent faculty members from applying and integrating technology in their classes.

It goes without saying that, how faculty members and university lecturers perceived the attributes of web based instruction influenced their teaching approaches and how to apply and integrate technology in their teaching activities. In case they found technology to be consistent with their mentality and their own values, they did not hesitate to apply and integrate it in their classes otherwise, they were very much likely to refuse integrating and applying it.. 
However, the findings of the study were proved to be different from the previous research in the way that no significant difference was observed between all the subscales of demographic variables and WBI application and integration in language classes. This can be due to the Asian setting as well as Asian approach they had toward teaching and teacher's role and status in the classes. They consider teacher as a sage in the stage, and seem to be reluctant to apply and integrate technology in their classes simply because they are afraid of losing their dominant status in the class.

\section{AUTHOR INFORMATION}

Sima Sayadian. Holding a BA in "English Translation" and an MA in "Language Teaching" from Iran, Sima Sayadian is currently pursuing her PhD in TESL at University Putra Malaysia. She has been teaching English at universities for the past ten years and has presented and published papers in several international conferences; her research interests include : Meaningful vs. Rote learning, Learner Autonomy, Learning Strategies, Attitudes and Motivation as well as Technology Adoption and Integration in Language Classes.

Dr. Jayakaran Mukundan teaches at the Faculty of Educational Studies, UPM, Malaysia. His main research interest lies in English Language Teaching Materials and he has won several research gold medals in this area. He is Visiting Fellow at Leeds Metropolitan University, UK. Dr. Mukundan is the Director of the Extensive Reading Foundation.

Dr.Rosalan Baki is Senior Lecturer at the Department of Language and Humanities Education, Faculty of Educational Studies, University Putra Malaysia. His research interest is in the areas of innovative language teaching, quality teaching and meaningful learning. He has written several books and published articles in local and international journals.

\section{REFERENCES}

1. Al-Fulih, K. (2002). Attributes of the Internet Perceived by Saudi Arabian Faculty as Predictors of their Internet Adoption for Academic Purposes. Doctoral Dissertation, Department of Educational Studies, Ohio University.

2. Al-Kahtani, Nouf, Ryan, J., \& Jefferson, T. (2006). How Saudi Female Faculty Perceive Internet Technology Usage and Potential. Information, Knowledge, Systems Management, Vol 5 No 6, pp. 227-243.

3. Al-Kahtani, S. (2001). Computer-Assisted Language Learning in EFL instruction at selected Saudi Arabian Universities: Profiles of Faculty. Unpublished doctoral dissertation, Indiana University of Pennsylvania.

4. Allehaibi, M. M. (2001). Faculty Adoption of Internet Technology in Saudi Arabian Universities. School of Information Studies, Florida State University. Doctoral Dissertation.

5. Al-Saif, A. A. (2005). The Motivating and Inhibiting Factors Affecting the Use of Web-Based Instruction at the University of Qassim in Saudi Arabia. Doctoral Dissertation, Wayne State University, Detroit, Michigan.

6. Cheng, Y., (2003)., Cheng. Y. (2003). The obstacle, model and recommendation for interdisciplinary research in research universities. Science of Science and Management of Science and Technology (China), 24(11): 77-80. (In Chinese)

7. Cuban, L. (1993). How teachers taught. New York: Teachers College Press.

8. Cunningham, 2001 Cunningham, K. (2000). Integrating CALL into the writing curriculum. The Internet TESL Journal, VI (5). Retrieved October 12, 2007, from http://iteslj.org/Articles/CunninghamCALLWriting

9. Groves and Zemel (2000) Groves, M. M., \& Zemel, P. C. (2000). Instructional technology adoption in higher education: An action research case study. International Journal of Instructional Media, 27(1), 57.

10. Heinecke, Blasi, Milman, \& Washington, 1999) Bull, G, Bull, G., Heinecke, W, Blasi, L., \& Willis, J. (1999). Collaborative education. Learning and Leading With Technology, 26(5), 48-52.

11. Heinecke, W.F, Dawson, K. M., Milman, N.B., Bartley, E., \& Blasi, L. (1999). Conditions, processes and consequences of teaching with technology: Results of a multiple case study. Paper presented at the 1999 Annual Meeting of the American Educational Research Association, Montreal, Canada. 
12. Kleiman, G. M. (2000, April-June). Myths and realities about technology in K-12 schools. LNT Perspectives: The Online Journal of the Leadership and the New Technologies Community, 14. [online] 9 pages. Available; http://www.edc.org/LNT/news/Issue14/feature1.htm

13. Knapp, L. R.\& Glenn A.D. (1996). Restructuring schools with technology. Boston: Allyn and Bacon.

14. Luan, W. S., Fung, N. S., Nawawi, M., \& Hong, T. S. (2005). Experienced and inexperienced Internet users among pre-service teachers: Their use and attitudes toward the Internet. Educational Technology \& Society, 8 (1), 90-103.

15. Marcinkiewicz, H. R. (1994). Computers and teachers: Factors influencing computer use in the classroom. Journal of Research on Computing in Education, 26(2), 220-237.

16. Masters, J.E \& Yelland, N.J. (2002) Teacher scaffolding: An exploration of exemplary practice. In D. Watson \& J. Anderson (Eds.). Networking the learner: Computers in Education. (pp 289\&\#8209;300) Boston: Kluwer

17. Moore and Benbasat (1991) : Moore, G. C. and I. Benbasat 'Development of an instrument to measure the perceptions of adopting an information technology innovation' Information Systems Research Vol 2 No 3 (1991) pp 173-191.

18. Naidu, S., Cunnington, D., \& Jasen, C. (2002). The Experience of Practitioners with Technology Enhanced Teaching and Learning. Educational Technology \& Society, 5 (1), 23-34.

19. Nations, N. (2000). Web-based Instruction. Retrieved January 20, 2003, from http://pt3.nmsu.edu/educ621/cynthia3.html

20. Passey, 1999; Don Passey: Preparing teachers for the connected learning community. Communications and Networking in Education 1999: 279-288

21. C. Pahl. 2003. Managing evolution and change in web-based teaching and learning environments. Computers \& Education, 40, 1, pp99-114.

22. Scanlon, E, Jones, A, Barnard, J, Thompson, J and Calder, J. (2000) "Evaluating information and communication technologies for learning", Educational Technology \& Society, Vol 3, No 4, pp 101-107.

23. Thelwall, M. (2000), Web Impact Factors and Search Engine Coverage. Journal of Documentation, 56(2), 185-189.

24. Wanjira Kinuthia,2005) Planning faculty development for successful implementation of web-based instruction. Campus-Wide Information Systems, 22, 4,189 - 200

25. Willis, D. W. 2004. Use of the case study method to enhance the educational experience for students. South Dakota State University Bush Project Anthology 1:38-41. 